\title{
GMR
}

\section{Genetic variation in $W D R 1$ is associated with gout risk and gout-related metabolic indices in the Han Chinese population}

\author{
L.J. Liu ${ }^{1,2 *}$, X.Y. Zhang ${ }^{3,4 *}$, N. He ${ }^{1,2}$, K Liu ${ }^{5}$, X.G. Shi ${ }^{1,2}$, T. Feng ${ }^{4}$, \\ T.T. Geng ${ }^{4}$, D.Y. Yuan ${ }^{1,2}$, L.L. Kang ${ }^{1,2}$ and T.B. Jin ${ }^{1,2,3,4}$ \\ ${ }^{1}$ Key Laboratory of High Altitude Environment and Genes Related to \\ Diseases of Tibet Autonomous Region, School of Medicine, \\ Xizang Minzu University, Xianyang, Shaanxi, China \\ ${ }^{2}$ Key Laboratory for Molecular Genetic Mechanisms and Intervention \\ Research on High Altitude Disease of Tibet Autonomous Region, \\ School of Medicine, Xizang Minzu University, Xianyang, Shaanxi, China \\ ${ }^{3}$ School of Life Sciences, Northwest University, Xi'an, China \\ ${ }^{4}$ National Engineering Research Center for Miniaturized Detection Systems, \\ Xi'an, China \\ ${ }^{5}$ Tibet Vocational Technical College, Tibet Autonomous Region, Lasa, China \\ *These authors contributed for this study. \\ Corresponding author: T.B. Jin \\ E-mail: jintianbo@gmail.com
}

Genet. Mol. Res. 15 (2): gmr.15027381

Received August 5, 2015

Accepted January 13, 2016

Published April 27, 2016

DOI http://dx.doi.org/10.4238/gmr.15027381

\begin{abstract}
Gout is the most common form of inflammatory arthritis affecting men, and current evidence suggests that genetic factors contribute to its progression. As a previous study identified that WD40 repeat protein 1 (WDRl) is associated with gout in populations of European descent, we sought to investigate its relationship with this disease in the Han Chinese population. We genotyped six WDR1 single nucleotide polymorphisms in 143 gout cases and 310 controls using
\end{abstract}


Sequenom MassARRAY technology. The SPSS 16.0 software was used to perform statistical analyses. Odds ratios (ORs) and $95 \%$ confidence intervals (CIs) were calculated by unconditional logistic regression, with adjustments for age and gender. In an analysis using an allelic model, we identified that the minor alleles of rs3756230 (OR $=0.64$, $95 \% \mathrm{CI}=0.450-0.911, \mathrm{P}=0.013)$ and $\mathrm{rs} 12498927(\mathrm{OR}=1.377,95 \% \mathrm{CI}$ $=1.037-1.831, \mathrm{P}=0.027)$ were associated with gout risk. In addition, we found that the "A/A" genotype of rs12498927 was associated with increased risk of gout under codominant $(\mathrm{OR}=2.22,95 \% \mathrm{CI}=1.12$ $4.40, \mathrm{P}=0.042)$ and recessive models $(\mathrm{OR}=2.24,95 \% \mathrm{CI}=1.20-4.17$, $\mathrm{P}=0.012$ ). We also determined the "A/G" genotype of rs 12498927 to be significantly associated with higher urea levels in gout patients ( $\mathrm{P}$ $=0.017)$. Our data shed new light on the association between genetic variations in the WDRl gene and gout susceptibility in the Han Chinese population.

Key words: WDR1; Single nucleotide polymorphism; Gout; Case-control study

\section{INTRODUCTION}

Gout is the most common type of inflammatory arthritis in men, with a prevalence of 1-2\% (Richette and Bardin 2010), and hyperuricemia has long been recognized as its most important risk factor (Riches et al. 2009). In the majority of gout patients, hyperuricemia occurs as a result of overproduction of uric acid (UA) or impaired excretion of renal UA (Terkeltaub et al., 2006). Previous studies have indicated that conventional risk factors including age, body mass index, cigarette smoking, and alcohol intake can influence serum UA concentration (Heinig and Johnson, 2006; Brandstätter et al., 2008; Haj Mouhamed et al., 2011). Moreover, serum UA levels are also determined by genetic factors, with heritability ranging from 25 to $63 \%$ (Yang et al., 2005; Doherty, 2009). To obtain a more complete understanding of predisposition to hyperuricemia and gout, identifying associated genetic risk factors is essential.

Recently, several independent genome-wide association scans have identified common single nucleotide polymorphisms (SNPs) associated with increased serum urate levels and gout in populations of European descent, involving genes including $S L C 2 A 9$, $A B C G 2$, SLC17A1, SLC17A3, WD40 repeat protein 1 (WDR1), and GCKR (McArdle et al., 2008; Vitart et al., 2008; Kolz et al., 2009; Charles et al., 2011; Köttgen et al., 2013). To date, however, WDR1 has not been as extensively studied, especially in the Chinese population. WDR1 is the vertebrate homolog of actin-interacting protein 1, and has been shown to contribute to GWAS association signals relating to serum UA levels and gout. In some investigations, WDRl expression has been observed to correlate with aging and inflammatory responses (Cervero et al., 2012).

We sought to investigate the potential role of WDRI SNPs in the development of gout among Han Chinese people. Therefore, we performed a comprehensive association analysis in northwest China, using a case-control design. Our data shed new light on the association between WDR1 SNPs and gout susceptibility in the Han Chinese population. 


\section{MATERIAL AND METHODS}

\section{Study population}

All study participants were Han Chinese. A total of 143 gout patients were consecutively recruited between March 2011 and November 2013 at the Affiliated Hospital of Tibet Institute for Nationalities and the Central Hospital in Xianyang City, China. All patients were recently diagnosed and histologically confirmed as suffering from gout according to the American College of Rheumatology classification criteria (1977), and as having no history of cancer, infection, nephropathy, or autoimmune diseases. No age, gender, or disease-stage restrictions were imposed for recruitment of cases.

We also recruited a random sample of unrelated healthy individuals between June 2010 and October 2011 from the medical examination center at the Affiliated Hospital of Tibet Institute For Nationalities in Xianyang City, China. All participants were Han Chinese and living in or near Xianyang city. Detailed recruitment and exclusion criteria were used in our study. Individuals were excluded if they had a history of cancer (based on self-reporting) or had received previous radiotherapy and/or chemotherapy for undisclosed conditions. This minimized the presence of factors that might have influenced mutation rate, thus maximizing the study power. In this way, we selected 310 unrelated healthy subjects to serve as controls.

Blood samples and signed informed consent forms were obtained from every participant. This protocol was approved by the Clinical Research Ethics Boards of Tibet University for Nationality and Northwest University, and complies with the Chinese Department of Health and Human Services regulations for the protection of human research subjects.

\section{Demographic and clinical data}

We collected demographic and clinical data via face-to-face interviews using a standardized epidemiological questionnaire, including information on gender, age, residential region, ethnicity, alcohol use, smoking status, educational status, and family history of cancer. Detailed clinical information on cases was collected from treating physicians or medical chart reviews. In addition, alpha-fetoprotein and plasma carcinoembryonic antigen levels were analyzed to ensure that no participants in the control group suffered from cancer.

\section{SNP selection and genotyping}

We selected SNPs from previously published polymorphisms associated with gout. Only SNPs with a minor allele frequency (MAF) greater than 5\% in the HapMap Han Chinese population were selected for genotyping, resulting in the use of six WDR1 SNPs. Genomic DNA was extracted from peripheral blood using the phenol-chloroform method, and its concentration was measured using a DU530 ultraviolet-visible spectrophotometer (Beckman Instruments, Fullerton, CA, USA). The MassARRAY Assay Design 3.0 software (Sequenom, San Diego, CA, USA) was used to design multiplex SNP MassEXTEND assays (Gabriel et al., 2009). Genotyping was performed using the Sequenom MassARRAY RS1000, following the manufacturer protocol (Gabriel et al., 2009), and data were managed using the Sequenom Typer 4.0 software (Sequenom; (Thomas et al., 2007; Gabriel et al., 2009). 


\section{Statistical analysis}

We used Excel (Microsoft, Redmond, WA, USA) and the SPSS 16.0 statistical package (SPSS Inc., Chicago, IL, USA) to perform statistical analyses. All P values in our study were two-sided, with $\mathrm{P}=0.05$ being considered the cutoff value for statistical significance. Control genotype frequencies for each SNP were tested for departure from Hardy-Weinberg equilibrium (HWE) using the Fisher exact test, while the chi-square test was used to compare genotype frequencies in case and control groups (Adamec, 1964). Unconditional logistic regression models adjusted for age and gender were used to derive odds ratios (ORs) and 95\% confidence intervals (CIs) (Bland and Altman, 2000) for gout susceptibility.

Associations between SNPs and gout risk were tested under several genetic models by analysis with the SNPStats software, obtained from http://bioinfo.iconcologia.net. OR and $95 \% \mathrm{CI}$ values were calculated as above. The Akaike and Bayesian information criteria were applied to choose the model of best fit for each SNP. Furthermore, we used analysis of variance (ANOVA) to compare gout-related clinical indices between the three different genotypes of the SNP significantly associated with this disease.

\section{RESULTS}

A total of 143 Han Chinese gout cases (125 men and 18 women, with a mean age of $43.17 \pm 14.06$ years) and 310 controls (197 men and 113 women, with a mean age of $49.09 \pm$ 7.88 years) were included in our study. Table 1 shows the demographic and clinical variables of the case and control subjects. Significant differences in gender and age distributions were observed between these two groups $(\mathrm{P}<0.05)$.

Table 1. Demographic and clinical variables in gout cases and healthy controls.

\begin{tabular}{l|c|c|c}
\hline & Cases & Controls & P value \\
\hline Total & 143 & 310 & $0.000^{\text {a* }}$ \\
\hline Gender & $18(12.4)$ & $113(36.5)$ & \\
\hline Women $(\%)$ & $125(86.2)$ & $197(63.5)$ & \\
\hline Men $(\%)$ & & & $0.000^{\text {b* }}$ \\
\hline Age & $43.17 \pm 14.061$ & & \\
\hline Mean \pm SD (years) & & & \\
\hline Clinical indices & $3.95 \pm 1.421$ & & \\
\hline TC $(\mathrm{mM})$ & $1.65 \pm 1.492$ & & \\
\hline TG $(\mathrm{mM})$ & $0.95 \pm 0.392$ & & \\
\hline HDL-C $(\mathrm{mM})$ & $2.08 \pm 0.837$ & & \\
\hline LDL-C $(\mathrm{mM})$ & $6.83 \pm 4.319$ & & \\
\hline Urea $(\mathrm{mM})$ & $507.15 \pm 100.343$ & & \\
\hline UA $(\mu \mathrm{M})$ & & & \\
\hline SD & & & \\
\hline
\end{tabular}

$\mathrm{SD}=$ standard deviation, $\mathrm{TC}=$ total cholesterol, $\mathrm{TG}=$ triglyceride, $\mathrm{HDL}-\mathrm{C}=$ high-density lipoprotein cholesterol, LDL-C $=$ low-density lipoprotein cholesterol, Urea = urea nitrogen, $\mathrm{UA}=$ uric acid. ${ }^{\mathrm{a} C a l c u l a t e d}$ by two-sided chisquare test. ${ }^{\mathrm{b}} \mathrm{Calculated}$ by independent samples $t$-test. ${ }^{*} \mathrm{P} \leq 0.05$ indicates statistical significance.

Table 2 summarizes the MAF of the SNPs tested among individuals in each group. None of these polymorphisms exhibited departure from HWE in the controls. Using the chisquare test to compare allele frequency distributions, we identified two SNPs in WDR1 that significantly differed between the study groups ( $\mathrm{rs} 3756230$ : $\mathrm{OR}=0.64,95 \% \mathrm{CI}=0.450-0.911$, $\mathrm{P}=0.013 ;$ rs $12498927: \mathrm{OR}=1.377,95 \% \mathrm{CI}=1.037-1.831, \mathrm{P}=0.027)$. 
Table 2. Allele frequencies in case and control groups and odds ratio estimates for association with gout.

\begin{tabular}{|c|c|c|c|c|c|c|c|c|c|}
\hline SNP & Gene & Location & Position & Minor allele & MAF (cases) & MAF (controls) & HWE P value & OR $(95 \% \mathrm{CI})$ & P value \\
\hline rs 3756230 & WDR1 & 4 p16.1 & 10083829 & $\mathrm{C}$ & 0.176 & 0.250 & 0.130 & $0.640(0.450-0.911)$ & $0.013^{*}$ \\
\hline rs3796818 & WDR1 & $4 \mathrm{p} 16.1$ & 10097976 & A & 0.134 & 0.181 & 0.128 & $0.702(0.473-1.042)$ & 0.078 \\
\hline rs2241488 & WDR1 & $4 \mathrm{p} 16.1$ & 10101131 & $\mathrm{C}$ & 0.134 & 0.181 & 0.128 & $0.702(0.473-1.042)$ & 0.078 \\
\hline rs 12509714 & WDR1 & 4 p16.1 & 10107091 & $\mathrm{C}$ & 0.479 & 0.424 & 0.131 & $1.25(0.944-1.653)$ & 0.119 \\
\hline rs 4604059 & WDR1 & $4 \mathrm{p} 16.1$ & 10115065 & $\mathrm{~T}$ & 0.421 & 0.355 & 0.106 & $1.32(0.993-1.756)$ & 0.056 \\
\hline rs12498927 & WDR1 & $4 \mathrm{p} 16.1$ & 10115523 & A & 0.434 & 0.358 & 0.064 & $1.377(1.037-1.831)$ & $0.027^{*}$ \\
\hline
\end{tabular}

$\mathrm{SNP}=$ single nucleotide polymorphism, $\mathrm{MAF}=$ minor allele frequency, $\mathrm{HWE}=$ Hardy-Weinberg equilibrium, $\mathrm{OR}$ $=$ odds ratio, $\mathrm{CI}=$ confidence interval. $* \mathrm{P} \leq 0.05$ indicates statistical significance.

In the genetic model component of our analysis, we assumed that the minor allele of each SNP was a risk factor relative to the wild-type allele. Five genetic models (dominant, recessive, additive, codominant, and overdominant) were applied to analyze associations between the SNPs and gout risk using a logistic regression test (Table 3). We found that the "A/A" genotype of rs12498927 was associated with increased gout risk, based on the codominant $(\mathrm{OR}=2.22,95 \% \mathrm{CI}=1.12-4.40, \mathrm{P}=0.042)$ and recessive models $(\mathrm{OR}=2.24$, $95 \% \mathrm{CI}=1.20-4.17, \mathrm{P}=0.012$ ). However, no association between rs3756230 and gout risk was identified after adjusting for gender and age.

Table 3. Logistic regression analysis of the association between the rs3756230 and rs12498927 polymorphisms and gout risk (adjusted for gender and age).

\begin{tabular}{|c|c|c|c|c|c|c|c|c|}
\hline SNP & Model & Genotype & Cases (\%) & Controls (\%) & $\mathrm{OR}(95 \% \mathrm{CI})$ & P value & AIC & $\mathrm{BIC}$ \\
\hline \multirow[t]{10}{*}{ rs 3756230} & \multirow[t]{3}{*}{ Codominant } & $\mathrm{G} / \mathrm{G}$ & $88(65.2)$ & $169(54.5)$ & 1 & \multirow[t]{3}{*}{0.29} & \multirow[t]{3}{*}{478.6} & \multirow[t]{3}{*}{499.1} \\
\hline & & $\mathrm{C} / \mathrm{G}$ & 44 (32.6) & $127(41)$ & $0.71(0.44-1.13)$ & & & \\
\hline & & $\mathrm{C} / \mathrm{C}$ & $3(2.2)$ & $14(4.5)$ & $0.57(0.14-2.27)$ & & & \\
\hline & \multirow[t]{2}{*}{ Dominant } & $\mathrm{G} / \mathrm{G}$ & $88(65.2)$ & $169(54.5)$ & 1 & \multirow[t]{2}{*}{0.12} & \multirow[t]{2}{*}{476.7} & \multirow[t]{2}{*}{493.1} \\
\hline & & $\mathrm{C} / \mathrm{G}-\mathrm{C} / \mathrm{C}$ & $47(34.8)$ & $141(45.5)$ & $0.70(0.44-1.10)$ & & & \\
\hline & \multirow[t]{2}{*}{ Recessive } & G/G-C/G & $132(97.8)$ & $296(95.5)$ & 1 & \multirow[t]{2}{*}{0.53} & \multirow[t]{2}{*}{478.7} & \multirow[t]{2}{*}{495.1} \\
\hline & & $\mathrm{C} / \mathrm{C}$ & $3(2.2)$ & $14(4.5)$ & $0.65(0.17-2.57)$ & & & \\
\hline & \multirow[t]{2}{*}{ Overdominant } & $\mathrm{G} / \mathrm{G}-\mathrm{C} / \mathrm{C}$ & $91(67.4)$ & $183(59)$ & 1 & \multirow[t]{2}{*}{0.18} & \multirow[t]{2}{*}{477.3} & \multirow[t]{2}{*}{493.7} \\
\hline & & $\mathrm{C} / \mathrm{G}$ & 44 (32.6) & $127(41)$ & $0.73(0.46-1.16)$ & & & \\
\hline & Log-additive & - & - & - & $0.72(0.48-1.09)$ & 0.12 & 476.7 & 493.1 \\
\hline \multirow[t]{10}{*}{ rs12498927 } & \multirow{3}{*}{ Codominant } & $\mathrm{G} / \mathrm{G}$ & $46(34.1)$ & $120(38.7)$ & 1 & \multirow[t]{3}{*}{$0.042^{*}$} & \multirow[t]{3}{*}{474.8} & \multirow[t]{3}{*}{495.3} \\
\hline & & $\mathrm{A} / \mathrm{G}$ & 64 (47.4) & $158(51)$ & $0.99(0.61-1.62)$ & & & \\
\hline & & $\mathrm{A} / \mathrm{A}$ & $25(18.5)$ & $32(10.3)$ & $2.22(1.12-4.40)$ & & & \\
\hline & \multirow[t]{2}{*}{ Dominant } & $\mathrm{G} / \mathrm{G}$ & $46(34.1)$ & $120(38.7)$ & 1 & \multirow[t]{2}{*}{0.47} & \multirow[t]{2}{*}{478.6} & \multirow[t]{2}{*}{495} \\
\hline & & $\mathrm{A} / \mathrm{G}-\mathrm{A} / \mathrm{A}$ & $89(65.9)$ & $190(61.3)$ & $1.19(0.75-1.88)$ & & & \\
\hline & \multirow[t]{2}{*}{ Recessive } & $\mathrm{G} / \mathrm{G}-\mathrm{A} / \mathrm{G}$ & $110(81.5)$ & $278(89.7)$ & 1 & \multirow[t]{2}{*}{$0.012^{*}$} & \multirow[t]{2}{*}{472.8} & \multirow[t]{2}{*}{489.2} \\
\hline & & $\mathrm{A} / \mathrm{A}$ & $25(18.5)$ & $32(10.3)$ & $2.24(1.20-4.17)$ & & & \\
\hline & \multirow[t]{2}{*}{ Overdominant } & $\mathrm{G} / \mathrm{G}-\mathrm{A} / \mathrm{A}$ & $71(52.6)$ & $152(49)$ & 1 & \multirow[t]{2}{*}{0.29} & \multirow[t]{2}{*}{478} & \multirow[t]{2}{*}{494.4} \\
\hline & & $\mathrm{A} / \mathrm{G}$ & 64 (47.4) & $158(51)$ & $0.79(0.51-1.23)$ & & & \\
\hline & Log-additive & - & - & - & $1.36(0.98-1.90)$ & 0.066 & 475.8 & 492.2 \\
\hline
\end{tabular}

$\mathrm{SNP}=$ single nucleotide polymorphism, $\mathrm{OR}=$ odds ratio, $\mathrm{CI}=$ confidence interval, $\mathrm{AIC}=$ Akaike's information criterion, $\mathrm{BIC}=$ Bayesian information criterion. ${ }^{*} \mathrm{P} \leq 0.05$ indicates statistical significance.

Finally, we compared gout-related clinical indices in gout patients between the three genotypes of rs12498927 using ANOVA. We found the "A/G" genotype of rs12498927 to be significantly associated with higher urea levels $(\mathrm{P}=0.017)$. However, UA concentration did not significantly differ with genotype (Table 4$)$. 
Table 4. Associations between different genotypes of rs12498927 and gout-related metabolic indices in gout patients.

\begin{tabular}{l|c|c|c|c|c|c|c}
\hline \multirow{2}{*}{ Variables } & \multicolumn{2}{|c|}{$\mathrm{A} / \mathrm{A}$} & \multicolumn{2}{|c|}{$\mathrm{A} / \mathrm{G}$} & \multicolumn{2}{c}{$\mathrm{G} / \mathrm{G}$} & $\mathrm{P}$ value \\
& $\mathrm{N}$ & Means \pm SD & $\mathrm{N}$ & Means \pm SD & $\mathrm{N}$ & Means \pm SD & \\
\hline TC $(\mathrm{mM})$ & 24 & $4.078 \pm 1.145$ & 62 & $3.934 \pm 1.719$ & 42 & $3.895 \pm 1.056$ & 0.877 \\
\hline TG $(\mathrm{mM})$ & 24 & $1.446 \pm 0.560$ & 61 & $1.777 \pm 1.995$ & 42 & $1.570 \pm 0.882$ & 0.607 \\
\hline HDL-C $(\mathrm{mM})$ & 24 & $1.091 \pm 0.536$ & 61 & $0.910 \pm 3.369$ & 42 & $0.921 \pm 0.312$ & 0.137 \\
\hline LDL-C $(\mathrm{mM})$ & 24 & $2.885 \pm 0.881$ & 61 & $2.049 \pm 0.920$ & 42 & $2.054 \pm 0.685$ & 0.781 \\
\hline Urea $(\mathrm{mM})$ & 21 & $5.144 \pm 1.061$ & 52 & $7.994 \pm 5.798$ & 34 & $6.084 \pm 1.662$ & $0.017 *$ \\
\hline UA $(\mu \mathrm{M})$ & 26 & $485.42 \pm 93.395$ & 68 & $517.25 \pm 115.931$ & 46 & $504.50 \pm 76.229$ & 0.382 \\
\hline
\end{tabular}

$\mathrm{TC}=$ total cholesterol, $\mathrm{TG}=$ triglyceride, $\mathrm{HDL}-\mathrm{C}=$ high-density lipoprotein cholesterol, $\mathrm{LDL}-\mathrm{C}=$ low-density lipoprotein cholesterol, Urea $=$ urea nitrogen, $\mathrm{UA}=$ uric acid. ${ }^{*} \mathrm{P} \leq 0.05$ indicates statistical significance.

\section{DISCUSSION}

In this case-control study carried out in China, we genotyped six WDR1 SNPs, finding that two of these (rs3756230 and rs 12498927) were significantly associated with gout. We also observed that the "A/A" genotype of rs12498927 was related to increased risk of gout based on analysis under various genetic models. In addition, the "A/G" genotype of rs 12498927 significantly correlated with higher urea levels in gout patients. Our findings suggest that genetic variations in WDR1 may contribute to incidence of this disease in the Han Chinese population.

WDR1, located on chromosome 4, is highly conserved in eukaryotes and promotes cofilin-mediated actin filament disassembly (Kato et al., 2008). A previous study demonstrated an association between WDRl and gout (Karns et al., 2012), but the biological mechanism responsible remains unclear. Kato et al. (2008) revealed that WDR1 plays an important role in unidirectional cell migration by promoting cofilin activity (Kato et al., 2008). In addition, Gearing et al. (2002) described aggregates of actin and cofilin in the brains of twins with dystonia and cleft lip and palate. Although neither of these studies establishes a direct link between WDR1 and gout, they do suggest a possible biological mechanism for gout paroxysm involving disruption of cell migration. We believe that this possibility is worthy of genetic and biological follow-up.

Studies of the WDR1 SNPs are rare, particularly those involving rs3756230 and rs12498927. One previous study of the influence of SNPs on serum UA concentration observed very strong long-range genomic interactions in female subjects between two WDRI SNPs (rs4604059 and rs12498927) and two intergenic SNPs (rs7681212 and rs11943276) near ZNF518B that were not seen in men (Wei et al., 2014). In our study, we found that the "A/A" genotype of rs12498927 was associated with a 2.22- and 2.24-fold increase in risk of developing gout under codominant and recessive models, respectively. However, the mechanisms by which these polymorphism effects such a change are not clear.

We also determined the "A/G" genotype of rs 12498927 to be significantly associated with higher urea levels in gout patients. We speculated that gene polymorphisms may play a role in increasing gout incidence by affecting protein metabolism. A previous study suggested that WDR1 may influence MAPK signaling pathway regulation, based on its interaction with other proteins (Fujibuchi et al., 2005). In addition, WDR1 may impact macrophage phagocytosis by regulating the degree of actin flip-flop, thereby affecting macrophage function and promoting gout-related inflammatory reactions (Kile et al., 2007). Based on these findings, it can be seen that WDR1 may indirectly affect gout development via MAPK signaling. 
Although the current study benefitted from sufficient statistical power, some limitations should be considered. Firstly, the sample size of our study was relatively small. Secondly, gout is known to be a very complicated disease and clinical indices are highly important in its study. However, as such measurements were absent from the control group data in our investigation, we were unable to explore how genetic polymorphisms and clinical indices interact in gout. Therefore, any association between WDRl gene polymorphism and clinical indices will need to be confirmed in future studies.

In conclusion, our comprehensive analysis of SNPs in the WDRl gene provides powerful new support for its relationship with gout susceptibility in the Han Chinese population. We report two novel SNPs and specific genotypes of these as being related to gout susceptibility. Our study offers important insights into the etiology of this disease.

\section{Conflicts of interest}

The authors declare no conflict of interest.

\section{ACKNOWLEDGMENTS}

Research supported by the National Natural Science Foundation of China (\#31260252), the Natural Science Foundation of Xizang (Tibet) Autonomous Region (\#20152R-13-11), and the Social Science Foundation of the Chinese Ministry of Education (\#12YJA850011).

\section{REFERENCES}

Adamec C (1964). Example of the use of the nonparametric test. Test X2 for comparison of 2 independent examples. Cesk. Zdrav. 12: 613-619.

Bland JM and Altman DG (2000). Statistics notes. The odds ratio. BMJ 320: 1468. http://dx.doi.org/10.1136/ bmj.320.7247.1468

Brandstätter A, Kiechl S, Kollerits B, Hunt SC, et al. (2008). Sex-specific association of the putative fructose transporter SLC2A9 variants with uric acid levels is modified by BMI. Diabetes Care 31: 1662-1667. http://dx.doi.org/10.2337/ dc08-0349

Cervero P, Himmel M, Krüger M and Linder S (2012). Proteomic analysis of podosome fractions from macrophages reveals similarities to spreading initiation centres. Eur. J. Cell Biol. 91: 908-922. http://dx.doi.org/10.1016/j. ejcb.2012.05.005

Charles BA, Shriner D, Doumatey A, Chen G, et al. (2011). A genome-wide association study of serum uric acid in African Americans. BMC Med. Genomics 4: 17. http://dx.doi.org/10.1186/1755-8794-4-17

Doherty M (2009). New insights into the epidemiology of gout. Rheumatology 48 (Suppl 2): ii2-ii8.

Fujibuchi T, Abe Y, Takeuchi T, Imai Y, et al. (2005). AIP1/WDR1 supports mitotic cell rounding. Biochem. Biophys. Res. Commun. 327: 268-275. http://dx.doi.org/10.1016/j.bbrc.2004.11.156

Gabriel S, Ziaugra L and Tabbaa D (2009). SNP genotyping using the Sequenom MassARRAY iPLEX platform. Curr. Protoc. Hum. Genet. Chapter 2: Unit 2.12.

Gearing M, Juncos JL, Procaccio V, Gutekunst CA, et al. (2002). Aggregation of actin and cofilin in identical twins with juvenile-onset dystonia. Ann. Neurol. 52: 465-476. http://dx.doi.org/10.1002/ana.10319

Haj Mouhamed D, Ezzaher A, Neffati F, Douki W, et al. (2011). Effect of cigarette smoking on plasma uric acid concentrations. Environ. Health Prev. Med. 16: 307-312. http://dx.doi.org/10.1007/s12199-010-0198-2

Heinig M and Johnson RJ (2006). Role of uric acid in hypertension, renal disease, and metabolic syndrome. Cleve. Clin. J. Med. 73: 1059-1064. http://dx.doi.org/10.3949/ccjm.73.12.1059

Karns R, Zhang G, Sun G, Rao Indugula S, et al. (2012). Genome-wide association of serum uric acid concentration: replication of sequence variants in an island population of the Adriatic coast of Croatia. Ann. Hum. Genet. 76: 121127. http://dx.doi.org/10.1111/j.1469-1809.2011.00698.x 
Kato A, Kurita S, Hayashi A, Kaji N, et al. (2008). Critical roles of actin-interacting protein 1 in cytokinesis and chemotactic migration of mammalian cells. Biochem. J. 414: 261-270. http://dx.doi.org/10.1042/BJ20071655

Kile BT, Panopoulos AD, Stirzaker RA, Hacking DF, et al. (2007). Mutations in the cofilin partner Aip1/Wdr1 cause autoinflammatory disease and macrothrombocytopenia. Blood 110: 2371-2380. http://dx.doi.org/10.1182/ blood-2006-10-055087

Kolz M, Johnson T, Sanna S, Teumer A, et al.; EUROSPAN Consortium; ENGAGE Consortium; PROCARDIS Consortium; KORA Study; WTCCC (2009). Meta-analysis of 28,141 individuals identifies common variants within five new loci that influence uric acid concentrations. PLoS Genet. 5: e1000504. http://dx.doi.org/10.1371/journal. pgen. 1000504

Köttgen A, Albrecht E, Teumer A, Vitart V, et al.; LifeLines Cohort Study; CARDIoGRAM Consortium; DIAGRAM Consortium; ICBP Consortium; MAGIC Consortium (2013). Genome-wide association analyses identify 18 new loci associated with serum urate concentrations. Nat. Genet. 45: 145-154. http://dx.doi.org/10.1038/ng.2500

McArdle PF, Parsa A, Chang YP, Weir MR, et al. (2008). Association of a common nonsynonymous variant in GLUT9 with serum uric acid levels in old order amish. Arthritis Rheum. 58: 2874-2881. http://dx.doi.org/10.1002/art.23752

Riches PL, Wright AF and Ralston SH (2009). Recent insights into the pathogenesis of hyperuricaemia and gout. Hum. Mol. Genet. 18 (R2): R177-R184. http://dx.doi.org/10.1093/hmg/ddp369

Richette P and Bardin T (2010). Gout. Lancet 375: 318-328. http://dx.doi.org/10.1016/S0140-6736(09)60883-7

Terkeltaub R, Bushinsky DA and Becker MA (2006). Recent developments in our understanding of the renal basis of hyperuricemia and the development of novel antihyperuricemic therapeutics. Arthritis Res. Ther. 8 (Suppl 1): S4. http://dx.doi.org/10.1186/ar1909

Thomas RK, Baker AC, Debiasi RM, Winckler W, et al. (2007). High-throughput oncogene mutation profiling in human cancer. Nat. Genet. 39: 347-351. http://dx.doi.org/10.1038/ng1975

Vitart V, Rudan I, Hayward C, Gray NK, et al. (2008). SLC2A9 is a newly identified urate transporter influencing serum urate concentration, urate excretion and gout. Nat. Genet. 40: 437-442. http://dx.doi.org/10.1038/ng.106

Wei WH, Guo Y, Kindt AS, Merriman TR, et al. (2014). Abundant local interactions in the 4p16.1 region suggest functional mechanisms underlying SLC2A9 associations with human serum uric acid. Hum. Mol. Genet. 23: 50615068. http://dx.doi.org/10.1093/hmg/ddu227

Yang Q, Guo CY, Cupples LA, Levy D, et al. (2005). Genome-wide search for genes affecting serum uric acid levels: the Framingham Heart Study. Metabolism 54: 1435-1441. http://dx.doi.org/10.1016/j.metabol.2005.05.007 